\title{
Probiotics and Respiratory Tract Diseases
}

\author{
Stefan Meuer \\ Institute of Immunology, University of Heidelberg, Heidelberg, Germany
}

Common infectious diseases (CID) of the airways and the gastrointestinal tract are still a considerable cause of morbidity and mortality in the elderly as aged people experience more frequent and severe community-acquired CID. Oral administration of specific probiotics has been reported to influence defense by the host in a beneficial way by modulating the immune system and increasing the transepithelial resistance [1-9]. Several studies documented that certain probiotics increase the number and activity of natural killer cells $[3,10]$, enhance antibody response to vaccination $[1,2,4,7]$ and increase the rate of seroprotection and seroconversion [1]. Probiotics were not only shown to enhance immune responses at the systemic level $[8,9]$, but there is also evidence for beneficial effects on the prevention and management of infections by probiotics [10].

For instance, it has been shown that probiotics reduce the risk of diarrhea including traveller's diarrhea [11-13]. Furthermore effects on the severity, duration and incidence of CID were demonstrated in a number of clinical trials $[4,14-25]$.

A meta-analysis of 8 controlled trials [26] showed a decrease in the occurrence of respiratory tract diseases as defined by the number of persons having at least 1 episode during the observation period. In this meta-analysis the severity and duration of the episodes was not significantly affected.

\section{KARGER \\ Fax +4161306 1234 \\ E-Mail karger@karger.ch \\ www.karger.com}

(C) 2010 S. Karger AG, Basel

0250-6807/10/0575-0024\$26.00/0

Accessible online at:

www.karger.com/anm
In a double-blind randomized controlled trial (DBRCT) in 1,000 shift workers [23] the intake of fermented milk drinks containing Lactobacillus casei DN114001 twice daily reduced the occurrence of CID during the cold season, the time until infections occurred and the duration of fever episodes. During infections the counts of leucocytes, granulocytes and natural killer cells were enhanced. In a multicentric, likewise DBRCT in 1,072 elderly the intake of the same drink reduced the mean duration of CID [24]. During the consumption period of 3 months the average duration of a CID episode has been significantly shortened to 6.5 versus 8 days in the control group ( $\mathrm{p}=0.008)$ as well as the cumulative duration of CID (7 vs. 8 days in the control group; $\mathrm{p}=$ $0.009)$. The reduction in both episode and cumulative duration was also significant for all upper respiratory tract infections and for rhinopharyngitis. In conclusion, the consumption of a fermented dairy product containing the probiotic strain L. casei DN-114 001 in elderly was associated with a decreased duration of CID and results in enhanced resistance of the elderly to CID.

Like elderly and shift workers, children show higher susceptibility to infections. Intense contacts in day care centers and schools predispose to transmissions of respiratory infections, which often result in missed days of both day care and parental work. Several studies have shown effects of probiotics on diarrhea [11-16]. In 
DBRCT in children aged 3-5 years L. acidophilus NCFM alone and together with Bifidobacterium animalis ssp. lactis $\mathrm{Bi} 07$ reduced the incidence of fever, cough and sneezing, their duration and the incidence of application of antibiotics [25]. Children receiving probiotic products were less absent from group child care, by $31.8 \%$ (single strain; $\mathrm{p}=0.002$ ) and $27.7 \%$ (strain combination; $\mathrm{p}<$ 0.001 ), compared with subjects receiving placebo treatment. Daily dietary probiotic supplementation for 6 months reduced fever, rhinorrhea and cough incidence and duration and antibiotic prescription incidence, as well as the number of missed school days attributable to illness.

Another recently published DBRCT examined the effect of a probiotic product containing L. casei DN-114 001 in 638 children 3-6 years old in day care/schools [27]. The incidence rate for CIDs in the active group was 19\% lower than that of the control group ( $\mathrm{p}=0.046)$. However, the effects of one product cannot be transferred to another. In a study recently conducted by the same working group [28] and following a similar study design, the strain B. animalis ssp. lactis (B. lactis) BB-12 did not show significant effects on CIDs. Therefore there is need for controlled clinical trials evaluating the health benefits of each probiotic food product containing well-defined probiotic strains.

There is increasing evidence for the efficacy of probiotics in respiratory tract diseases, which may justify the application of certain probiotics in this area.

\section{Disclosure Statement}

S.M. is a member of Danone's scientific advisory board.

\section{References}

$>1$ Boge T, Rémigy M, Vaudaine S, Tanguy J, Bourdet-Sicard R, van der Werf S: A probiotic fermented dairy drink improves antibody response to influenza vaccination in the elderly in two randomised controlled trials. Vaccine 2009;27:5677-5684.

$\checkmark 2$ Borchers AT, Keen CL, Gershwin ME: The influence of yogurt/Lactobacillus on the innate and acquired immune response. Clin Rev Allergy Immunol 2002;22:207-230.

>3 Gill HS, Rutherfurd KJ, Cross ML, Gopal PK: Enhancement of immunity in the elderly by dietary supplementation with the probiotic Bifidobacterium lactis HN019. Am J Clin Nutr 2001;74:833-839.

$\checkmark 4$ De Vrese M, Winkler P, Rautenberg P, Harder T, Noah C, Laue C, Ott S, Hampe J, Schreiber S, Heller K, Schrezenmeir J: Effect of Lactobacillus gasseri PA 16/8, Bifidobacterium longum SP 07/3, B. bifidum MF 20/5 on common cold episodes: a double blind, randomized, controlled trial. Clin Nutr 2005;24: 481-491.

$>5$ Gareau MG, Jury J, MacQueen G, Sherman PM, Perdue MH: Gut 2007;56:1522-1528.

$\checkmark 6$ Ghadimi D, Vrese MD, Heller KJ, Schrezenmeir J: Effect of natural commensal-origin DNA on toll-like receptor 9 (TLR9) signaling cascade, chemokine IL- 8 expression, and barrier integritiy of polarized intestinal epithelial cells. Inflamm Bowel Dis 2010;16: 410-427.
7 Lara-Villoslada F, Sierra S, Boza J, Xaus J, Olivares M: Beneficial effects of consumption of a dairy product containing two probiotic strains, Lactobacillus coryniformis CECT5711 and Lactobacillus gasseri CECT5714 in healthy children. Nutr Hosp 2007;22:496-502.

8 Marcos A, Wärnberg J, Nova E, Gómez S, Alvarez A, Alvarez R, Mateos JA, Cobo JM: The effect of milk fermented by yogurt cultures plus Lactobacillus casei DN-114001 on the immune response of subjects under academic examination stress. Eur J Nutr 2004;43: 381-389.

-9 Parra MD, Martínez de Morentin BE, Cobo JM, Mateos A, Martínez JA: Daily ingestion of fermented milk containing Lactobacillus casei DN114001 improves innate-defense capacity in healthy middle-aged people. J Physiol Biochem 2004;60:85-91.

10 Wolvers D, Antoine JM, Myllyluoma E, Schrezenmeir J, Szajewska H, Rijkers GT: Guidance for substantiating the evidence for beneficial effects of probiotics: prevention and management of infections by probiotics. J Nutr 2010;140:698S-712S.

11 Sazawal S, Hiremath G, Dhingra U, Malik P, Deb S, Black RE: Efficacy of probiotics in prevention of acute diarrhoea: a meta-analysis of masked, randomised, placebo-controlled trials. Lancet Infect Dis 2006;6:374382.

-12 Szajewska H, Skórka A, Dylag M: Meta-analysis: Saccharomyces boulardii for treating acute diarrhoea in children. Aliment Pharmacol Ther 2007;25:257-264.
13 McFarland LV: Meta-analysis of probiotics for the prevention of traveler's diarrhea. Travel Med Infect Dis 2007;5:97-105.

14 Pedone CA, Arnaud CC, Postaire ER, Bouley CF, Reinert P: Multicentric study of the effect of milk fermented by Lactobacillus casei on the incidence of dia. Int J Clin Pract 2000;54: 568-571.

15 Pedone CA, Bernabeu AO, Postaire ER, Bouley CF, Reinert P: The effect of supplementation with milk fermented by Lactobacillus casei (strain DN-114 001) on acute diarrhoea in children attending day care centres. Int J Clin Pract 1999;53:179-184.

16 Agarwal KN, Bhasin SK, Faridi MM, Mathur M, Gupta S: Lactobacillus casei in the control of acute diarrhea - a pilot study. Indian $\mathrm{Pe}$ diatr 2001;38:905-910.

17 Hatakka K, Savilahti E, Pönkä A, Meurman JH, Poussa T, Näse L, Saxelin M, Korpela R: Effect of long-term consumption of probiotic milk on infections in children attending day care centres: double blind, randomised trial. BMJ 2001;322:1327.

-18 Turchet P, Laurenzano M, Auboiron S, Antoine JM: Effect of fermented milk containing the probiotic Lactobacillus casei DN114001 on winter infections in free-living elderly subjects: a randomised, controlled pilot study. J Nutr Health Aging 2003;7:75-77.

19 Lodinová-Zádníková R, Cukrowska B, Tlaskalova-Hogenova $\mathrm{H}$ : Oral administration of probiotic Escherichia coli after birth reduces frequency of allergies and repeated infections later in life (after 10 and 20 years). Int Arch Allergy Immunol 2003;131:209-211. 
20 Tubelius P, Stan V, Zachrisson A: Increasing workplace healthiness with the probiotic Lactobacillus reuteri: a randomised, doubleblind placebo-controlled study. Environ Health 2005;4:25.

21 De Vrese M, Winkler P, Rautenberg P, Harder T, Noah C, Laue C, Ott S, Hampe J, Schreiber S, Heller K, Schrezenmeir J: Probiotic bacteria reduced duration and severity but not the incidence of common cold episodes in a double blind, randomized, controlled trial. Vaccine 2006;24:6670-6674.

22 Weizman Z, Asli G, Alsheikh A: Effect of a probiotic infant formula on infections in child care centers: comparison of two probiotic agents. Pediatrics 2005;115:5-9.

23 Schrezenmeir J, Guillemard E, Tanguy J, Flavigny $A$, de la Motte S: Consumption of fermented dairy product containing the probiotic Lactobacillus casei DN 114001 reduces the incidence of common respiratory and gastrointestinal infections in shift workers in a randomized controlled trial. Clin Nutr 2009; 421 .
24 Guillemard E, Tondu F, Lacoin F, Schrezenmeir J: Consumption of a fermented dairy product containing the probiotic Lactobacillus casei $\mathrm{DN}-114001$ reduces the duration of respiratory infections in the elderly in a randomised controlled trial. Br J Nutr 2010;103: 58-68.

25 Leyer GJ, Li S, Mubasher ME, Reifer C, Ouwehand AC: Probiotic effects on cold and influenza-like symptom incidence and duration in children. Pediatrics 2009;124:172179.

26 Offick B: Effects of probiotics on immunity - studies on mechanisms and clinical outcome in infections and allergic diseases (dissertation thesis), Kiel, 2009.
27 Merenstein D, Murphy M, Fokar A, Hernandez RK, Park H, Nsouli H, Sanders ME, Davis BA, Niborski V, Tondu F, Shara NM: Use of a fermented dairy probiotic drink containing Lactobacillus casei (DN-114 001) to decrease the rate of illness in kids: the DRINK study - A patient-oriented, doubleblind, cluster-randomized, placebo controlled, clinical trial. Eur J Clin Nutr 2010, Epub ahead of print.

28 Merenstein D, Smith KH, Scriven M, Roberts RF, Sanders ME, Petterson S: The study to investigate the potential benefits of probiotics in yogurt, a patient-oriented, doubleblind, cluster-randomised, placebo-controlled, clinical trial. Eur J Clin Nutr 2010, Epub ahead of print. 